\title{
Phylogenetic analysis of members of the genus Aeromonas based on gyrB gene sequences
}

\author{
M. A. Yáñez, ${ }^{1,2}$ V. Catalán, ${ }^{2}$ D. Apráiz, ${ }^{2}$ M. J. Figueras ${ }^{3}$ \\ and A. J. Martínez-Murcia ${ }^{1}$ \\ ${ }^{1}$ Unidad de Diagnóstico Molecular, EPSO, Universidad Miguel Hernández, Ctra Beniel Km 3, \\ E-03312 Orihuela (Alicante), Spain \\ ${ }^{2}$ Labaqua SA, Alona 33, E-03007 Alicante, Spain \\ 3Unidad de Microbiología, Departamento de Ciencias Médicas Básicas, Facultad de Medicina y \\ Ciencias de la Salud, Universidad Rovira y Virgili, Reus, E-43201 Tarragona, Spain
}

\begin{abstract}
The phylogenetic relationships of all known species of the genus Aeromonas were investigated by using the sequence of $g y r B$, a gene that encodes the B-subunit of DNA gyrase. Nucleotide sequences of $g y r B$ were determined from 53 Aeromonas strains, including some new isolates, which were also characterized by analysis of the $16 \mathrm{~S}$ rDNA variable regions. The results support the recognition of the family Aeromonadaceae, as distinct from Plesiomonas shigelloides and other enteric bacteria. This phylogenetic marker revealed strain groupings that are consistent with the taxonomic organization of all Aeromonas species described to date. In particular, gyrB results agreed with $16 \mathrm{~S}$ rDNA analysis; moreover, the former showed a higher capacity to differentiate between species. The present analysis was useful for the elucidation of reported discrepancies between different DNA-DNA hybridization sets. Additionally, due to the sequence diversity found at the intraspecies level, gyrB is proposed as a useful target for simultaneous identification of species and strains. In conclusion, the gyrB gene has proved to be an excellent molecular chronometer for phylogenetic studies of the genus Aeromonas.
\end{abstract}

\section{INTRODUCTION}

The genus Aeromonas comprises a collection of oxidaseand catalase-positive, glucose-fermenting, facultatively anaerobic, Gram-negative, rod-shaped bacteria that are resistant to the vibriostatic agent $\mathrm{O} / 129$ and are generally motile by means of polar flagella (Popoff, 1984). Aeromonads are autochthonous to aquatic environments worldwide and have been implicated in the aetiology of a variety of fish and human diseases, frequently including diarrhoea and occasionally systemic infections (Janda, 1991). Over the past few years, interest in the genus Aeromonas as an emergent human pathogen has increased significantly (Abbott et al., 1998; Janda \& Abbott, 1998; Joseph \& Carnahan, 2000).

Published online ahead of print on 29 November 2002 as DOI 10.1099/ijs.0.02443-0.

Abbreviation: HG, homology group.

The GenBank/EMBL/DDBJ accession numbers for the gyrB sequences of Aeromonas species determined in this study are AY101772-AY101824.

Tables showing percentage similarities and percentage nucleotide substitutions in gyrB in the genus Aeromonas are available as supplementary data in IJSEM Online.
The classification of the genus Aeromonas has been dogged by confusion and controversy. In Bergey's Manual of Systematic Bacteriology (Popoff, 1984), the genus was divided into three mesophilic and motile species (Aeromonas hydrophila, Aeromonas caviae and Aeromonas sobria) and the psychrophilic, non-motile species Aeromonas salmonicida. Extensive DNA-DNA hybridization studies (Popoff et al., 1981; Hickman-Brenner et al., 1987, 1988; Kuijper et al., 1989; Carnahan et al., 1991) have resulted in the recognition of 14 so-called DNA homology groups (HGs): A. hydrophila (HG1), Aeromonas sp. (unnamed; HG2), A. salmonicida (HG3), A. caviae (HG4), Aeromonas media (HG5), Aeromonas eucrenophila (HG6), A. sobria (HG7), Aeromonas veronii biogroup sobria (HG8), Aeromonas jandaei (HG9), A. veronii biogroup veronii (HG10), Aeromonas sp. (unnamed; HG11), A. schubertii (HG12), Aeromonas group 501 (HG13; formerly Enteric group 501) and Aeromonas trota (HG14). The name Aeromonas bestiarum has been proposed for strains included in HG2 (Ali et al., 1996). During the past decade, three novel species have been described: Aeromonas allosaccharophila (Martínez-Murcia et al., 1992b), Aeromonas encheleia (Esteve et al., 1995b) and Aeromonas popoffii (Huys et al., 1997b). The species names Aeromonas enteropelogenes and Aeromonas ichthiosmia (Schubert et al., 1990a, b) are now 
Table 1. Aeromonas strains used in this study

Corresponding DNA HG is indicated. ATCC, American Type Culture Collection, Manassas, VA, USA; CCUG, Culture Collection of the University of Göteborg, Göteborg, Sweden; CDC, Centers for Disease Control, United States Public Health Service, Atlanta, GA, USA; CECT, Colección Española de Cultivos Tipo, Universidad de Valencia, Valencia, Spain; CIP, Collection Bactérienne de l'Institut Pasteur, Paris, France; DSM, Deutsche Sammlung von Mikroorganismen und Zellkulturen, Braunschweig, Germany; LMG, Culture Collection of the Laboratorium voor Microbiologie Gent, Universiteit Gent, Gent, Belgium; NCIMB, National Culture Collection of Industrial and Marine Bacteria, Aberdeen, Scotland, UK.

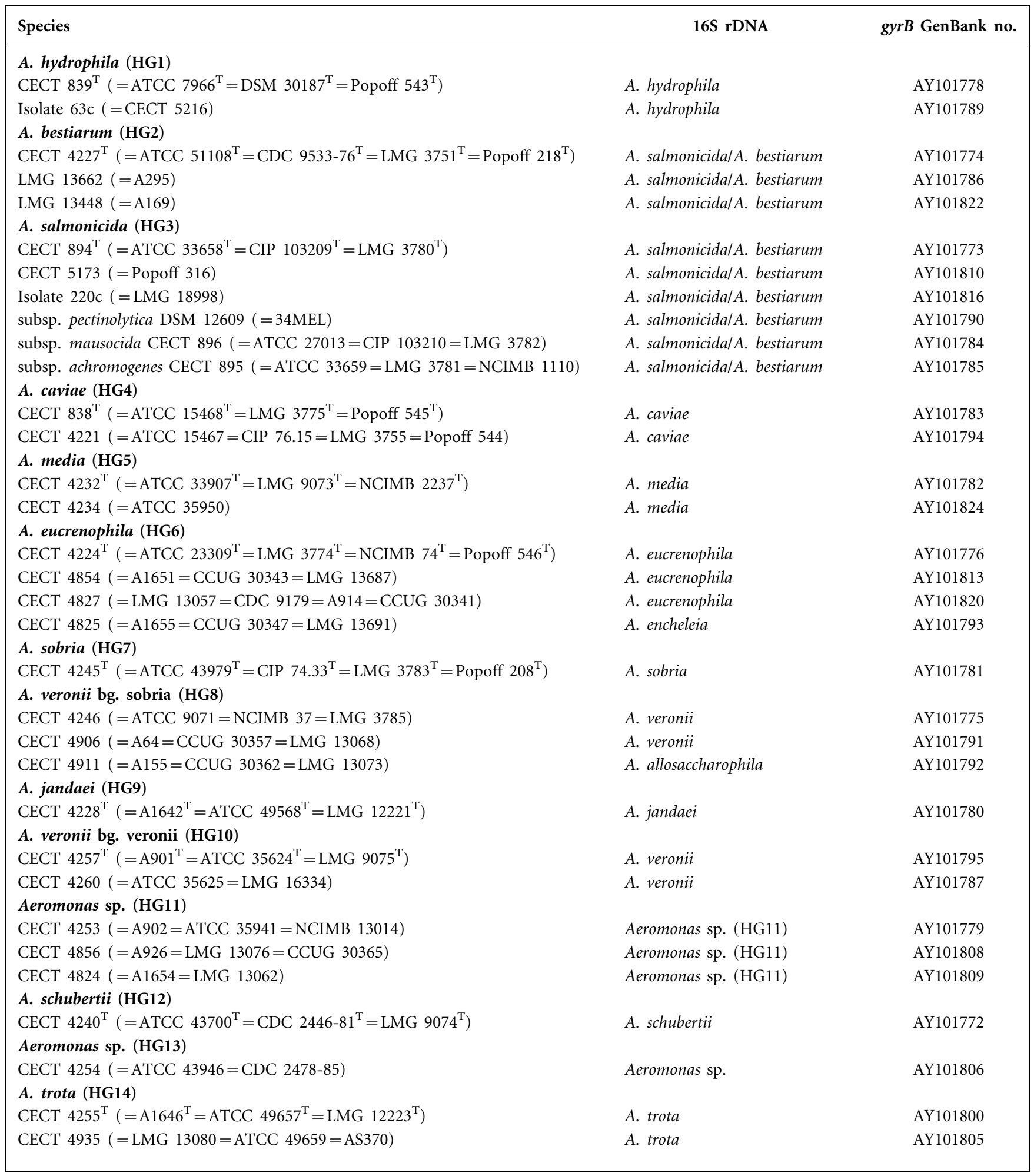


Table 1. cont.

\begin{tabular}{|c|c|c|}
\hline Species & 16S rDNA & gyrB GenBank no. \\
\hline \multicolumn{3}{|l|}{ A. allosaccharophila (HG15) } \\
\hline CECT $4199^{\mathrm{T}}\left(=\right.$ ATCC $51208^{\mathrm{T}}=$ CCUG $\left.31218^{\mathrm{T}}=\mathrm{S} 289^{\mathrm{T}}=\mathrm{LMG} 14059^{\mathrm{T}}\right)$ & A. allosaccharophila & AY101777 \\
\hline CECT $4200(=$ S290=LMG 14058) & A. allosaccharophila & AY101823 \\
\hline \multicolumn{3}{|l|}{ A. encheleia (HG16) } \\
\hline CECT $4342^{\mathrm{T}}\left(=\right.$ ATCC $\left.51929^{\mathrm{T}}=\mathrm{S} 181^{\mathrm{T}}=\mathrm{NCIMB} 13442^{\mathrm{T}}\right)$ & A. encheleia & AY101799 \\
\hline \multicolumn{3}{|l|}{ A. popoffii (HG17) } \\
\hline CECT $5176^{\mathrm{T}}\left(=\mathrm{LMG} 17541^{\mathrm{T}}=\mathrm{IK}-\mathrm{O}-\mathrm{a}-10-3^{\mathrm{T}}\right)$ & A. popoffii & AY101801 \\
\hline LMG 17543 & A. popoffii & AY101803 \\
\hline LMG 17544 & A. popoffii & AY101821 \\
\hline \multicolumn{3}{|l|}{ Aeromonas sp. } \\
\hline Isolate $531 \mathrm{c}$ & Newly described (not shown) & AY101817 \\
\hline Isolate 610 & Newly described (not shown) & AY101814 \\
\hline Isolate 520 & Newly described (not shown) & AY101811 \\
\hline Isolate CFAE 35 & Newly described (not shown) & AY101798 \\
\hline Isolate $350 \mathrm{c}$ & A. sobria & AY101807 \\
\hline Isolate 344 & A. jandaei & AY101796 \\
\hline Isolate $16 \mathrm{~s}-93$ & A. veronii & AY101797 \\
\hline CECT $5026(=$ LMG $16405=\mathrm{KV} 78=\mathrm{A} 1785)$ & Newly described (not shown) & AY101818 \\
\hline
\end{tabular}

considered to be synonyms of $A$. trota and $A$. veronii, respectively (Carnahan, 1993; Collins et al., 1993). Phylogenetic analyses based on $16 \mathrm{~S}$ rRNA genes indicated that aeromonads are a very tight group of species (MartinezMurcia et al., 1992a). In almost all species of the genus, rDNA-derived relationships correlated well with DNADNA hybridization. DNA probes and RFLP profiles designed from 16S rDNA diagnostic regions have served to identify Aeromonas at the species level (Ash et al., 1993a, b; Dorsch et al., 1994; Borrell et al., 1997; Khan \& Cerniglia, 1997; Figueras et al., 2000). However, there are reported discrepancies between different sets of DNA-DNA hybridization data (Hickman-Brenner et al., 1987; Schubert \& Hegazi, 1988; Esteve et al., 1995a, b; Huys et al., 1996a, b, 2001), and the fact that $16 \mathrm{~S}$ rRNA is highly conserved (Martínez-Murcia, 1999) brings the latest descriptions of some species into question (Nair \& Holmes, 1999).

It has been reported that $g y r B$ (which encodes the B-subunit of DNA gyrase, a type-II DNA topoisomerase) could be a suitable phylogenetic marker for bacterial systematics (Yamamoto \& Harayama, 1995, 1996, 1998; Huang, 1996; Venkateswaran et al., 1998; Yamamoto et al., 1999, 2000; Kasai et al., 2000; Watanabe et al., 2001; Stackebrandt et al., 2002). This protein plays a crucial role in the DNA replication process, and its gene sequence has a mean synonymous substitution rate that is almost four times that of 16S rDNA (Yamamoto \& Harayama, 1996).
In the present study, gyrB nucleotide sequences were determined from 53 Aeromonas strains, including type strains of all described species (or HGs), reference strains and some new isolates, which were also characterized by analysis of the $16 \mathrm{~S}$ rDNA variable regions. This phylogenetic study was designed to clarify the interspecies phylogenetic relationships within Aeromonas, and to assess the congruence of $\operatorname{gyrB}$ groupings with those of both $16 \mathrm{~S}$ rDNA sequencing and DNA-DNA hybridization.

\section{METHODS}

Bacterial strains and culture conditions. Bacterial strains used in this study are listed in Table 1 . New isolates and reference strains from culture collections were identified genetically by $16 \mathrm{~S}$ rDNA RFLP typing and further sequencing. Most Aeromonas strains were grown aerobically on trypticase soy agar (Oxoid) overnight at $28^{\circ} \mathrm{C}$. The only exception was the psychrophilic species A. salmonicida, which was incubated at $22^{\circ} \mathrm{C}$.

DNA extraction and purification. A single colony from a fresh culture was resuspended in $50 \mu \mathrm{l}$ TE buffer, vortexed at high speed for $1 \mathrm{~min}$ and incubated at $96^{\circ} \mathrm{C}$ for $10 \mathrm{~min}$. The tube was vortexed again and centrifuged for $2 \mathrm{~min}$ at $12000 \mathrm{~g}$. The supernatant was transferred to a fresh tube and stored at $-20^{\circ} \mathrm{C}$.

Oligonucleotide primers. Primers gyrB3F and gyrB14R were designed from the most conserved regions in a preliminary alignment of published A. hydrophila gyrB sequences (GenBank accession numbers AF074917 and AF208250-AF208260). These primers were used to amplify a $g y r B$ fragment of approximately $1100 \mathrm{bp}$. Primers 
Table 2. Characteristics of primers used for PCR amplification and sequencing of $g y r B$

\begin{tabular}{|lcc|}
\hline Primer & Position $^{*}$ & Sequence $\left(\mathbf{5}^{\prime} \mathbf{- 3}^{\prime}\right)$ \\
\hline gyrB3F & $334-354$ & TCCGGCGGTCTGCACGGCGT \\
gyrB7F & $792-812$ & GGGGTCTACTGCTTCACCAA \\
gyrB9R & $979-959$ & ACCTTGACGGAGATAACGGC \\
gyrB9Rs & $980-960$ & CCTTGACCGAAATGACCGCC \\
gyrB14R & $1464-1444$ & TTGTCCGGGTTGTACTCGTC \\
\hline
\end{tabular}

${ }^{\star}$ According to E. coli numbering.

gyrB7F, gyrB9R and gyrB9Rs were then designed from alignments that included the first few $g y r B$ sequences obtained in the present study. The five Cy5-labelled primers (Table 2) were purchased from Amersham Biosciences and were used for $g y r B$ sequencing reactions as required. Primers for amplification and sequencing of $16 \mathrm{~S}$ rDNA were described previously (Martínez-Murcia et al., 1999).

PCR amplification and sequencing. PCR amplification was performed using a GeneAmp PCR System 9700 thermal cycler (Applied Biosystems). Each reaction was performed in a final volume of $50 \mu \mathrm{l}$, containing $50 \mathrm{mM} \mathrm{KCl}, 10 \mathrm{mM}$ Tris/ $\mathrm{HCl}(\mathrm{pH} 9 \cdot 0), 1.5 \mathrm{mM}$ $\mathrm{MgCl}_{2}, 0 \cdot 1 \%$ Triton X-100, $0 \cdot 2 \mathrm{mM}$ each dNTP (Roche Diagnostics), $1 \mathrm{U}$ Taq DNA polymerase (Amersham Biosciences), 20 pmol each primer and $1 \mu \mathrm{l}$ DNA sample. The reaction mixture was subjected to 35 cycles of amplification as follows: denaturation at $94{ }^{\circ} \mathrm{C}$ for $30 \mathrm{~s}$, annealing at $55^{\circ} \mathrm{C}$ for $30 \mathrm{~s}$ and extension at $72{ }^{\circ} \mathrm{C}$ for $1 \mathrm{~min}$. Amplified products were analysed by electrophoresis on $1.2 \%$ agarose-TBE gels, stained with ethidium bromide $\left(0 \cdot 5 \mu \mathrm{g} \mathrm{ml}^{-1}\right)$ and visualized on a UV transilluminator. PCR products were purified using the Concert Rapid PCR Purification system (Invitrogen Life Technologies), following the manufacturer's instructions. Nucleotide sequences were determined by using the Thermo Sequenase fluorescentlabelled primer cycle sequencing kit with 7-deaza-dGTP in an ALFexpressII automatic DNA sequencer (both from Amersham Biosciences), according to the manufacturer's instructions, using Cy5-labelled primers.

Phylogenetic data analysis. The gyrB nucleotide sequences were aligned by using the CLUSTAL X program, version 1.8 (Thompson et al., 1997). Genetic distances were obtained using Kimura's twoparameter model (Kimura, 1980) and evolutionary trees were constructed by the neighbour-joining method (Saitou \& Nei, 1987) with the MEGA program (Kumar et al., 2001).

\section{RESULTS AND DISCUSSION}

Nucleotide sequences of gyrB amplicons from 53 Aeromonas strains were determined (Table 1). Experiments were repeated at least twice from single colonies of original cultures, to confirm readings and solve ambiguities. The derived gyrB sequences were 960-1100 nt in length, covering more than $70 \%$ of the ATPase domain (amino acid residues 2-392 in Escherichia coli; Huang, 1996) and $191 \mathrm{nt}$ of the $3^{\prime}$ flanking region. Species identification by $16 \mathrm{~S}$ rDNA sequence is shown in Table 1.

\section{Phylogenetic location of the genus Aeromonas}

A multiple alignment of the GyrB subunit amino acid sequences, deduced from the gene sequences, was obtained.
Amino acid (289 aa) and nucleotide (869 bp) sequences from type strains of all known Aeromonas species (or HGs) were compared with the corresponding sequences of the species E. coli, Vibrio cholerae, P. shigelloides, Neisseria gonorrhoeae and Myxococcus xanthus. Percentage similarities for both proteins and genes are given in Table A, which is available as supplementary data in IJSEM Online. On average, protein sequences showed a higher level of conservation than nucleotide sequences. Ranges of nucleotide and protein sequence similarity values between Aeromonas and species of other genera were, respectively: $68 \cdot 5-70 \cdot 9 \%$ and $75 \cdot 1-77 \cdot 2 \%$ to $V$. cholerae; $72 \cdot 0-74 \cdot 0 \%$ and $74 \cdot 7-$ $76 \cdot 8 \%$ to P. shigelloides; and $73 \cdot 9-76 \cdot 1 \%$ and $75 \cdot 7-76 \cdot 5 \%$ to E. coli. A phylogenetic tree constructed from the nucleotide alignment is shown in Fig. 1.

It is evident from the phylogenetic tree shown in Fig. 1 that the genus Aeromonas formed a distinct line, separate from $V$. cholerae and E. coli, as it did from P. shigelloides. Species of these four genera belong to the $\gamma$-subclass of the Proteobacteria, clearly separated from representatives of

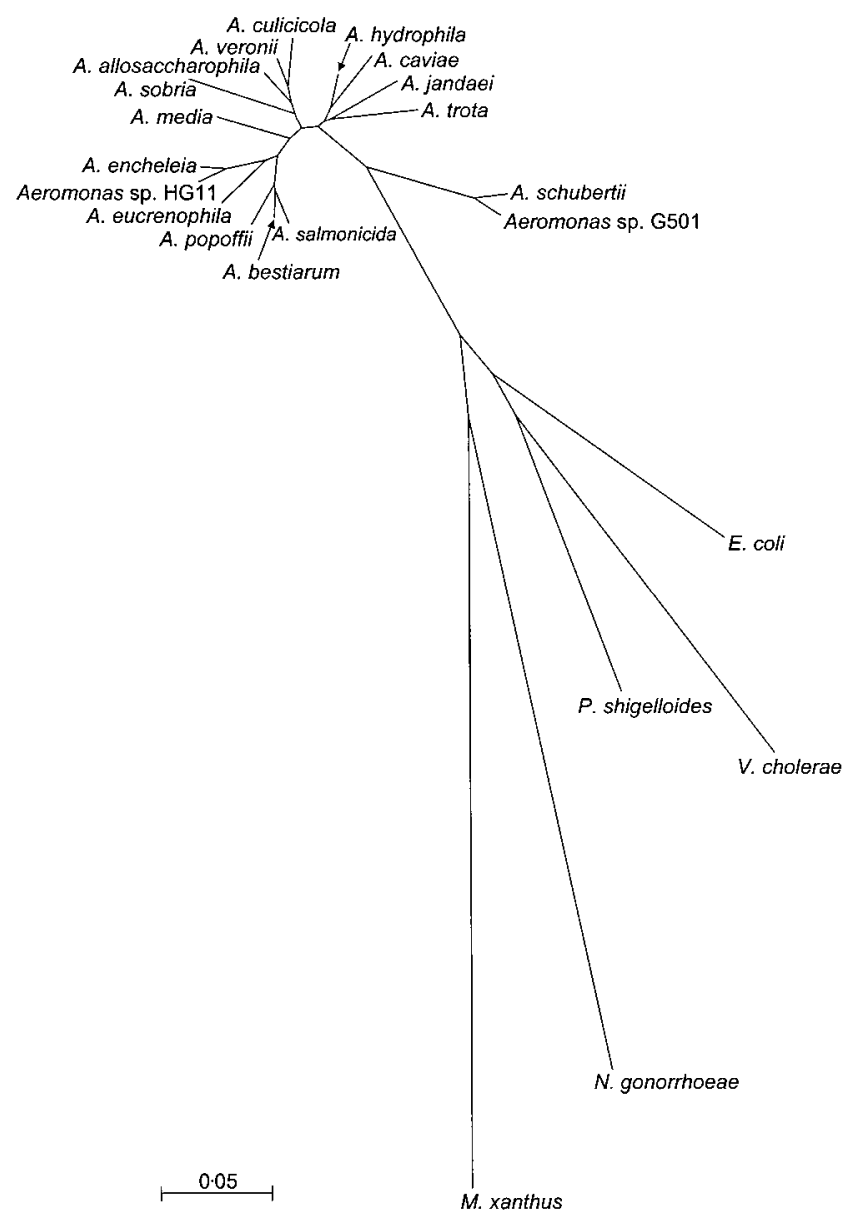

Fig. 1. Neighbour-joining tree based on gyrB sequences showing the relationships of type strains of all known Aeromonas species to some representative members of the class Proteobacteria. 
the $\beta$ - (N. gonorrhoeae) and $\delta$ - (M. xanthus) subclasses. These findings agree with a previous phylogenetic study based on 16S rRNA gene sequences (Martinez-Murcia et al., 1992a) and support recognition of the family Aeromonadaceae (Colwell et al., 1986). In addition, the aeromonads showed a lower interspecies gyrB substitution rate than that of other genera (Yamamoto et al., 1999, 2000), in agreement with the former hypothesis that Aeromonas are a group of bacteria that have evolved relatively recently (MartínezMurcia, 1999; Martínez-Murcia et al., 1999).

\section{Phylogenetic relationships of Aeromonas species}

The gyrB sequences from all Aeromonas strains in this study were aligned, and percentage nucleotide substitutions (Table B, available as supplementary data in IJSEM Online) were calculated for a continuous stretch of $957 \mathrm{nt}$ (positions 404-1364 according to the E. coli numbering). Sequence similarity between Aeromonas strains ranged from $86 \cdot 7$ to $100 \%$, corresponding to $0-127$ nucleotide differences. At the intraspecies level, the rate of nucleotide substitution ranged from 0 to $2 \cdot 6 \%$, and was $<2 \%$ for most Aeromonas species. However, interspecies nucleotide substitutions were usually $>3 \%$, except for the following two pairs of species: $A$. salmonicida and A. bestiarum $(2 \cdot 2-3 \cdot 3 \%)$, and $A$. encheleia and Aeromonas sp. HG11 $(2 \cdot 1-2 \cdot 7 \%)$. Fig. 2 shows an unrooted tree that was constructed from the derived genetic distance matrix by the neighbour-joining method. The same topology (phylogenetic distances and branching points) was obtained when only $772 \mathrm{bp}$, corresponding to approximately $70 \%$ of the ATPase domain, was used (not shown).

The results of this phylogenetic analysis demonstrate that, in the genus Aeromonas, gyrB sequences show a mean substitution rate that is approximately six times higher than that of 16S rRNA (Martinez-Murcia et al., 1992a). This faster rate is an expected consequence of the chronometric nature of the $\operatorname{gyr} B$ gene as, although relatively conserved because it encodes a housekeeping enzyme, it is subject to a degenerative code which allows most silent mutations to occur (i.e. different codons may encode the same amino acid). Such evolutionary differences between the gyrB gene and protein chronometers are shown in Table A (available as supplementary data in IJSEM Online) where, apart from

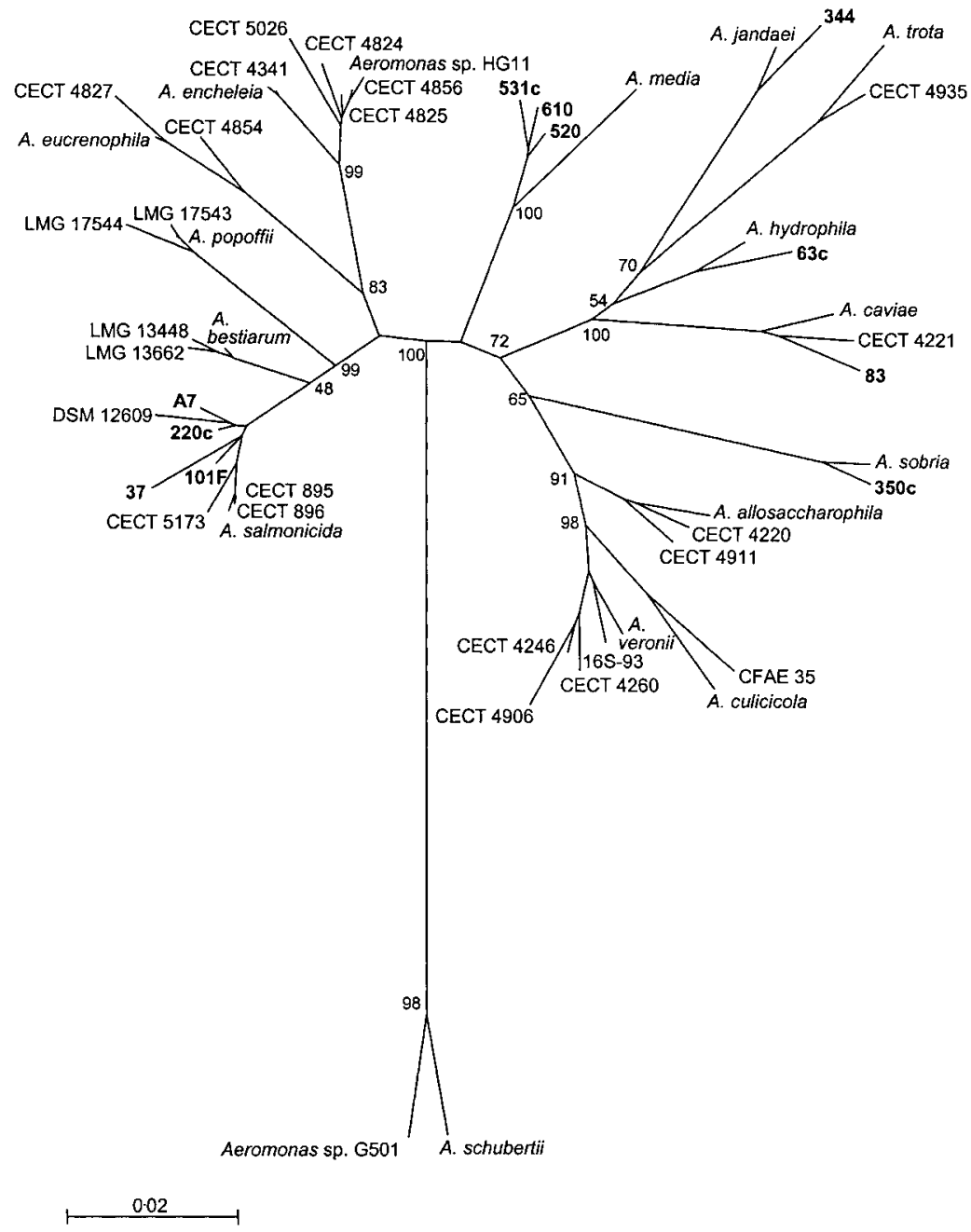

Fig. 2. Neighbour-joining tree based on gyrB sequences showing the inter- and intraspecies relationships of the genus Aeromonas. Species names correspond to type strains. Numbers in bold correspond to new Aeromonas isolates. Numbers shown next to each node indicate bootstrap values (percentage of 1000 replicates). 
a higher level of protein conservation, different nucleotide sequences often encode almost-identical GyrB proteins. As a consequence, phylogenetic trees obtained from the protein sequences (not shown) show poor branching resolution and many strains of different species appear intermixed. Instead, gyrB gene sequences were found to be extremely useful in the current phylogenetic study of the genus Aeromonas.

Sequence analysis of $g y r B$ shows considerable divergence between all Aeromonas species and DNA HGs. Moreover, apart from the strains A. media CECT 4234 and A. allosaccharophila CECT 4200, which showed sequences identical to those of the corresponding type strains of these species, a significant number of differences were found between strains of the same species. The two exceptions may suggest that these strains are duplicates of the type strains of their respective species. All other strains had a unique $g y r B$ sequence; it therefore appears that $\operatorname{gyr} B$ sequences may be used not only for species identification, but also for simultaneous research of the phylogenetic depth of species. Despite the observed sequence diversity at the strain level, the groupings shown in Fig. 2 indicate a phylogenetic taxonomy consistent with that described in most previous genetic and phylogenetic studies of the genus Aeromonas. Almost all species formed separate lines on the basis of their $g y r B$ sequences and clearly represent distinct genospecies. Due to the fact that $\operatorname{gyr} B$ sequence divergence is greater than that of $16 \mathrm{~S}$ rRNA, we found the former gene more advantageous for Aeromonas species delineation. For example, A. trota and A. caviae, distinguishable by only a single nucleotide of their $16 \mathrm{~S}$ rDNA sequences, are separated at a relatively large phylogenetic distance (Fig. 2) on the basis of partial gyrB sequence $(6 \cdot 0-7 \cdot 2 \%$ nucleotide substitutions, corresponding to $57-69 \mathrm{bp}$; see Table B in the supplementary data available in IJSEM Online). Similarly, A. hydrophila and A. media, which show only three nucleotide differences in $16 \mathrm{~S}$ rDNA, are clearly separated by gyrB sequences (Fig. 2). A. schubertii clustered at the deepest branch of the genus (near the ancestral root), which is consistent with the 16S rRNA tree (MartínezMurcia, 1999). The present analysis confirms that A. veronii biogroup sobria (HG8) and biogroup veronii (HG10) represent two heterogeneous phenotypes of a single species. Strain CECT 4911 (LMG 13073), largely classified as A. veronii (Huys et al., 1996b), possessed a gyrB sequence that was clearly related to that of $A$. allosaccharophila (Fig. 2). 16S rDNA sequencing results (Table 1) confirmed that CECT 4911 actually belongs to A. allosaccharophila.

Our study included the $g y r B$ sequence from the type strain of the recently described species Aeromonas culicicola (Pidiyar et al., 2002), available in GenBank (accession no. AF175891). This taxon, together with isolate CFAE 35 (previously identified as A. eucrenophila; Singh \& Sanyal, 1999), formed a separate phylogenetic line as shown in the tree in Fig. 2. The closest relatives of this species were A. veronii and A. allosaccharophila $(3 \cdot 4-4 \cdot 0$ and $3 \cdot 9-4 \cdot 4 \%$ sequence divergence, respectively; Table B); therefore, these three species are equidistant from each other. The $16 \mathrm{~S}$ rRNA gene of $A$. culicicola showed only a single nucleotide difference from that of $A$. jandaei CECT $4228^{\mathrm{T}}$. On the other hand, 56 differences (in approx. $1000 \mathrm{nt}$ ) were found in the $g y r B$ gene, once again demonstrating the advantage of this gene in separating closely related species.

\section{The species $A$. allosaccharophila}

Previous amplified fragment length polymorphism (AFLP) and DNA-DNA hybridization studies by Huys et al. (1996b, 2001) have questioned the original proposal of the species A. allosaccharophila, which was based on phylogenetic and phenotypic analyses (Martínez-Murcia et al., 1992b) and subsequent DNA-DNA reassociation results obtained by Esteve et al. (1995a). The latter study found that strains of A. allosaccharophila exhibited $0-40 \%$ DNA relatedness with A. veronii, although later DNA-DNA hybridization studies by Huys et al. (2001) indicated a much higher range of $78-84 \%$, using the same reference strains. Apart from the striking lack of correlation between these hybridization studies, another inconsistency was found for the strain A. allosaccharophila CECT 4220 (ATCC 35942) when compared with DNA-DNA hybridization data obtained by Hickman-Brenner et al. (1987). It is worth nothing that Huys et al. often reported relatively high DNA relatedness values between very unrelated Aeromonas species (MartínezMurcia, 1999; Huys et al., 2001). In the original description of A. allosaccharophila (Martínez-Murcia et al., 1992b), it was concluded that the species shows a clear phylogenetic divergence, demonstrated by qualitative evolutionary events (as well as the quantitative differences indicated) that support its phylogenetic distinctiveness from other species and particularly from $A$. veronii. The $16 \mathrm{~S}$ rDNA of A. allosaccharophila shows six unique bases, i.e. different composition at positions where all other known Aeromonas species have the same conserved nucleotides (a fact that obviously gives more support to the distinctiveness of this species); also, A. allosaccharophila can be readily distinguished from $A$. veronii in region V2 (by two paired signature triplets at positions $154-156$ and 167-165), the most relevant evolutionary event that splits the genus Aeromonas between A. hydrophila and A. schubertii. In the present study, A. allosaccharophila, although one of the closest phylogenetic relatives of $A$. veronii, undoubtedly formed a separate line on the basis of the gyrB sequence analysis, a result consistent with the phylogenetic analysis based on 16S rDNA (Martínez-Murcia et al., 1992b). The rate of nucleotide differences in their gyrB sequences varies from 2.9 to $4 \cdot 1 \%$, which is notable considering the mean intraspecies value in Aeromonas (approx. 2\%). In comparison, similar phylogenetic distances were found between A. veronii and A. culicicola, or between A. popoffii and $A$. bestiarum. In view of the present and previous studies, we consider that $A$. allosaccharophila shows sufficient phylogenetic divergence to be considered as a separate species. 


\section{Controversial taxonomic issues}

An insertion of $3 \mathrm{bp}$ at positions 484-485 (E. coli numbering) was only detected in all strains of the species A. salmonicida and A. bestiarum (triplet AGC), A. popoffii and Aeromonas sp. HG11 (triplet AGT) and A. encheleia and A. eucrenophila (triplet TCC). All of these species clustered together in the same sub-branch of the tree (Fig. 2). Although this codon encodes serine in all strains of these species, its composition was found to be variable, even in the first codon position (i.e. AGC, AGT and TCC). Because the insertion was found neither in other Aeromonas species nor in representatives of the other genera studied, we consider this to be an exclusive character of this group of species, and as support for the hypothesis that these species have evolved from each other relatively recently. Curiously, this group contains species that show the lowest range of gyrB nucleotide differences; this has been considered to be one of the most controversial taxonomic issues of the genus Aeromonas.

A. salmonicida and A. bestiarum have $2 \cdot 2-3 \cdot 3 \%$ nucleotide substitutions in $g y r B$, which is on the border between the intra- and interspecies ranges observed in the present study. Previous 16S rDNA results have indicated that these two species are only distinguishable by two paired nucleotides at positions 1011 and 1018 (Martínez-Murcia, 1999). However, some strains of A. salmonicida have shown $16 \mathrm{~S}$ rDNA sequences identical to that of the type strain of A. bestiarum, which is consistent with the difficulties found in the separation of strains of HG2 and HG3 by DNADNA hybridization (Hänninen, 1994; Ali et al., 1996). Composition of the inserted codon in gyrB is the same for these two species (and different from all others), adding support for their close phylogenetic relationship. Strains of $A$. popoffii appear to be closely related to A. bestiarum on the basis of $\operatorname{gyrB}$ sequence $(2 \cdot 9-3 \cdot 6 \%$ divergence), in agreement with DNA-DNA hybridization data from the description of A. popoffii (Huys et al., 1997b), which showed the highest value $(51-63 \%)$ with A. bestiarum. Although the species are very closely related, $A$. popoffii warrants separate species status, as supported by $16 \mathrm{~S}$ rDNA phylogeny (Martínez-Murcia, 1999) and RFLP analysis of the 16S-23S intergenic spacer region (A. J. Martínez-Murcia and others, unpublished data).

A second example of controversy within the genus Aeromonas is represented by $A$. encheleia and the unnamed Aeromonas sp. HG11. The gyrB sequences determined in the present study indicate that these species are closely related, as the interspecies divergence was in the range $2 \cdot 1-2 \cdot 7 \%$. The composition of the inserted codon is different for these two species. Classification of strains into one of these species has been very difficult (MartínezMurcia, 1999). For example, strain CECT 4824 (LMG 13062), formerly classified as A. eucrenophila (Huys et al., 1996a), showed 94\% DNA-DNA hybridization with A. encheleia CECT $4342^{\mathrm{T}}$ (Huys et al., 1997a), but a value of $82 \%$ hybridization with A. eucrenophila was reported in a previous study (Schubert \& Hegazi, 1988). On the basis of gyrB sequence, this strain clearly clustered with Aeromonas sp. HG11, a result supported by $16 \mathrm{~S}$ rDNA sequence analysis (Martínez-Murcia, 1999). Similarly, A. eucrenophila strain CECT 4825 (LMG 13691) has shown $50 \%$ (Huys et al., 1997a) and 80\% (Schubert \& Hegazi, 1988) DNA-DNA hybridization with A. eucrenophila LMG $3774^{\mathrm{T}}$. The current $\operatorname{gyr} B$ sequence analysis indicates that this strain belongs to the Aeromonas sp. HG11 (Fig. 2), but its partial 16S rDNA sequence shows highest similarity to $A$. encheleia (Table 1 ). The $16 \mathrm{~S}$ rDNA divergence between A. encheleia and Aeromonas sp. HG11 is based on eight nucleotide differences (Martínez-Murcia, 1999), which at first seems sufficient for a genus as tight as Aeromonas. All eight nucleotide differences were located at hypervariable positions (457-476) of a stem-loop with secondary structure base-pairing, rather than being dispersed around the molecule. This causes some concerns, as molecular clock 'distortions' (i.e. plesiomorphy) detected on variable stem-loops have previously been reported for closely related individuals (Sneath, 1993; Martínez-Murcia et al., 1999). Consequently, further investigation using a considerable number of newly isolated A. encheleia/HG11 strains is recommended.

A similar case has been detected in the present study. Three isolates, $610,520 \mathrm{c}$ and $531 \mathrm{c}$, formed a separate cluster on the basis of $\operatorname{gyrB}$ sequences (Fig. 2), but the cluster was closely related to $A$. media $(2 \cdot 7-3 \cdot 1 \%$ substitutions). The distinctiveness of these isolates from A. media was also supported by $16 \mathrm{~S}$ rDNA sequencing (data not shown); however, nucleotide differences were again located in the stem-loop at position 460 in the V3 region.

In conclusion, the $\operatorname{gyrB}$ gene sequence has proved to be an excellent molecular chronometer for phylogenetic inference in the genus Aeromonas. This phylogenetic marker revealed strain groupings consistent with the taxonomy proposed in most previous genetic and phylogenetic studies, particularly in agreement with $16 \mathrm{~S}$ rDNA sequence analysis. The present analysis may serve to elucidate reported discrepancies between different DNA-DNA hybridization datasets. In addition, the observed sequence diversity at the intraspecies level allows us to propose that $g y r B$ may be useful for strain differentiation and, at the same time, for identification of species following a phylogenetic frame.

\section{ACKNOWLEDGEMENTS}

M. A. Y. was the recipient of an MIT grant from Ministerio de Ciencia y Tecnología. This work has been supported by grants FIS 99/0944 from Ministerio de Salud y Consumo, and GV98-21-05 from Generalitat Valenciana. We would like to thank the Colección Española de Cultivos Tipo (CECT) and Dr Durg V. Singh, Rajiv Gandhi Centre for Biotechnology, Jagathy, Kerala, India, for providing strains.

\section{REFERENCES}

Abbott, S. L., Seli, L. S., Catino, M., Jr, Hartley, M. A. \& Janda, J. M. (1998). Misidentification of unusual Aeromonas species as members 
of the genus Vibrio: a continuing problem. J Clin Microbiol 36, 1103-1104.

Ali, A., Carnahan, A. M., Altwegg, M., Lüthy-Hottenstein, J. \& Joseph, S. W. (1996). Aeromonas bestiarum sp. nov. (formerly genomospecies DNA group 2 A. hydrophila), a new species isolated from non-human sources. Med Microbiol Lett 5, 156-165.

Ash, C., Martínez-Murcia, A. J. \& Collins, M. D. (1993a). Identification of Aeromonas schubertii and Aeromonas jandaei by using a polymerase chain reaction-probe test. FEMS Microbiol Lett 108, 151-156.

Ash, C., Martínez-Murcia, A. J. \& Collins, M. D. (1993b). Molecular identification of Aeromonas sobria by using a polymerase chain reaction-probe test. Med Microbiol Lett 2, 80-86.

Borrell, N., Acinas, S. G., Figueras, M. J. \& Martínez-Murcia, A. J. (1997). Identification of Aeromonas clinical isolates by restriction fragment length polymorphism of PCR-amplified 16S rRNA genes. $J$ Clin Microbiol 35, 1671-1674.

Carnahan, A. M. (1993). Aeromonas taxonomy: a sea of change. 4th International Workshop on Aeromonas/Plesiomonas, Atlanta, GA. Med Microbiol Lett 2, 206-211.

Carnahan, A. M., Chakraborty, T., Fanning, G. R., Verma, D., Ali, A., Janda, J. M. \& Joseph, S. W. (1991). Aeromonas trota sp. nov., an ampicilin-susceptible species isolated from clinical specimens. J Clin Microbiol 29, 1206-1210.

Collins, M. D., Martinez-Murcia, A. J. \& Cai, J. (1993). Aeromonas enteropelogenes and Aeromonas ichthiosmia are identical to Aeromonas trota and Aeromonas veronii, respectively, as revealed by small-subunit rRNA sequence analysis. Int J Syst Bacteriol 43, 855-856.

Colwell, R. R., MacDonell, M. T., O’Brien, M. \& De Ley, J. (1986). Proposal to recognize the family Aeromonadaceae fam. nov. Int J Syst Bacteriol 36, 473-477.

Dorsch, M., Ashbolt, N. J., Cox, P. T. \& Goodman, A. E. (1994). Rapid identification of Aeromonas species using 16S rDNA targeted oligonucleotide primers: a molecular approach based on screening of environmental isolates. J Appl Bacteriol 77, 722-726.

Esteve, C., Gutiérrez, M. C. \& Ventosa, A. (1995a). DNA relatedness among Aeromonas allosaccharophila strains and DNA hybridization groups of the genus Aeromonas. Int J Syst Bacteriol 45, 390-391.

Esteve, C., Gutiérrez, M. C. \& Ventosa, A. (1995b). Aeromonas encheleia sp. nov., isolated from European eels. Int J Syst Bacteriol 45, 462-466.

Figueras, M. J., Soler, L., Chacón, M. R., Guarro, J. \& MartínezMurcia, A. J. (2000). Extended method for discrimination of Aeromonas spp. by $16 \mathrm{~S}$ rDNA RFLP analysis. Int $J$ Syst Evol Microbiol 50, 2069-2073.

Hänninen, M.-L. (1994). Phenotypic characteristics of the three hybridization groups of Aeromonas hydrophila complex isolated from different sources. J Appl Bacteriol 76, 455-462.

Hickman-Brenner, F. W., MacDonald, K. L., Steigerwalt, A. G., Fanning, G. R., Brenner, D. J. \& Farmer, J. J., III (1987). Aeromonas veronii, a new ornithine decarboxlase-positive species that may cause diarrhea. J Clin Microbiol 25, 900-906.

Hickman-Brenner, F. W., Fanning, G. R., Arduino, M. J., Brenner, D. J. \& Farmer, J. J., III (1988). Aeromonas schubertii, a new mannitolnegative species found in human clinical specimens. J Clin Microbiol 26, 1561-1564.

Huang, W. M. (1996). Bacterial diversity based on type II DNA topoisomerase genes. Annu Rev Genet 30, 79-107.

Huys, G., Altwegg, M. Hänninen, M.-L. \& 7 other authors (1996a). Genotypic and chemotaxonomic description of two subgroups in the species Aeromonas eucrenophila and their affiliation to A. encheleia and Aeromonas DNA hybridization group 11. Syst Appl Microbiol 19, 616-623.

Huys, G., Coopman, R., Janssen, P. \& Kersters, K. (1996b). Highresolution genotypic analysis of the genus Aeromonas by AFLP fingerprinting. Int J Syst Bacteriol 46, 572-580.

Huys, G., Kämpfer, P., Altwegg, M., Coopman, R., Janssen, P., Gillis, M. \& Kersters, K. (1997a). Inclusion of Aeromonas DNA hybridization group 11 in Aeromonas encheleia and extended descriptions of the species Aeromonas eucrenophila and A. encheleia. Int J Syst Bacteriol 47, 1157-1164.

Huys, G., Kämpfer, P., Altwegg, M. \& 7 other authors (1997b). Aeromonas popoffii sp. nov., a mesophilic bacterium isolated from drinking water production plants and reservoirs. Int J Syst Bacteriol 47, 1165-1171.

Huys, G., Kämpfer, P. \& Swings, J. (2001). New DNA-DNA hybridization and phenotypic data on the species Aeromonas ichthiosmia and Aeromonas allosaccharophila: A. ichthiosmia Schubert et al. 1990 is a later synonym of A. veronii HickmanBrenner et al. 1987. Syst Appl Microbiol 24, 177-182.

Janda, J. M. (1991). Recent advances in the study of the taxonomy, pathogenicity, and infectious syndromes associated with the genus Aeromonas. Clin Microbiol Rev 4, 397-410.

Janda, J. M. \& Abbott, S. L. (1998). Evolving concepts regarding the genus Aeromonas: an expanding panorama of species, disease presentations, and unanswered questions. Clin Infect Dis 27, 332-344.

Joseph, S. W. \& Carnahan, A. M. (2000). Update on the genus Aeromonas. ASM News 66, 218-223.

Kasai, H., Ezaki, T. \& Harayama, S. (2000). Differentiation of phylogenetically related slowly growing mycobacteria by their gyrB sequences. J Clin Microbiol 38, 301-308.

Khan, A. A. \& Cerniglia, C. E. (1997). Rapid and sensitive method for the detection of Aeromonas caviae and Aeromonas trota by polymerase chain reaction. Lett Appl Microbiol 24, 233-239.

Kimura, M. (1980). A simple method for estimating evolutionary rates of base substitutions through comparative studies of nucleotide sequences. J Mol Evol 16, 111-120.

Kuijper, E. J., Steigerwalt, A. G., Schoenmakers, B. S. C. I. M., Peeters, M. F., Zanen, H. C. \& Brenner, D. J. (1989). Phenotypic characterization and DNA relatedness in human fecal isolates of Aeromonas spp. J Clin Microbiol 27, 132-138.

Kumar, S., Tamura, K., Jakobsen, I. B. \& Nei, M. (2001). MEGA2: molecular evolutionary genetics analysis software. Bioinformatics 17, 1244-1245.

Martínez-Murcia, A. J. (1999). Phylogenetic positions of Aeromonas encheleia, Aeromonas popoffi, Aeromonas DNA hybridization Group 11 and Aeromonas Group 501. Int J Syst Bacteriol 49, 1403-1408.

Martinez-Murcia, A. J., Benlloch, S. \& Collins, M. D. (1992a). Phylogenetic interrelationships of members of the genera Aeromonas and Plesiomonas as determined by $16 \mathrm{~S}$ ribosomal DNA sequencing: lack of congruence with results of DNA-DNA hybridizations. Int J Syst Bacteriol 42, 412-421.

Martínez-Murcia, A. J., Esteve, C., Garay, E. \& Collins, M. D. (1992b). Aeromonas allosaccharophila sp. nov., a new mesophilic member of the genus Aeromonas. FEMS Microbiol Lett 91, 199-205.

Martínez-Murcia, A. J., Antón, A. I. \& Rodríguez-Valera, F. (1999). Patterns of sequence variation in two regions of the 16S rRNA multigene family of Escherichia coli. Int J Syst Bacteriol 49, 601-610. Nair, G. B. \& Holmes, B. (1999). International Committee on Systematic Bacteriology Subcommittee on the Taxonomy of Vibrionaceae. Minutes of the closed meeting, 19 May 1998, Atlanta, GA, USA. Int J Syst Bacteriol 49, 1945-1947. 
Pidiyar, V., Kaznowski, A., Badri Narayan, N., Patole, M. \& Shouche, Y. S. (2002). Aeromonas culicicola sp. nov., from the midgut of Culex quinquefasciatus. Int J Syst Evol Microbiol 52, 1723-1728.

Popoff, M. (1984). Genus III. Aeromonas Kluyver and Van Niel 1936, $398^{\mathrm{AL}}$. In Bergey's Manual of Systematic Bacteriology, vol. 1, pp. 545-548. Edited by N. R. Krieg \& J. G. Holt. Baltimore: Williams \& Wilkins.

Popoff, M. Y., Coynault, C., Kiredjian, M. \& Lemelin, M. (1981). Polynucleotide sequence relatedness among motile Aeromonas species. Curr Microbiol 5, 109-114.

Saitou, N. \& Nei, M. (1987). The neighbor-joining method: a new method for reconstructing phylogenetic trees. Mol Biol Evol 4, 406-425.

Schubert, R. H. W. \& Hegazi, M. (1988). Aeromonas eucrenophila species nova, Aeromonas caviae a later and illegitimate synonym of Aeromonas punctata. Zentbl Bakteriol Mikrobiol Hyg 1 Abt Orig A 268, 34-39.

Schubert, R. H. W., Hegazi, M. \& Wahlig, W. (1990a). Aeromonas enteropelogenes species nova. Hyg Med 15, 471-472.

Schubert, R. H. W., Hegazi, M. \& Wahlig, W. (1990b). Aeromonas ichthiosmia species nova. Hyg Med 15, 477-479.

Singh, D. V. \& Sanyal, S. C. (1999). Virulence patterns of Aeromonas eucrenophila isolated from water and infected fish. J Diarrhoeal Dis Res 17, 37-42.

Sneath, P. H. A. (1993). Evidence from Aeromonas for genetic crossing-over in ribosomal sequences. Int J Syst Bacteriol 43, 626-629.

Stackebrandt, E., Frederiksen, W., Garrity, G. M. \& 10 other authors (2002). Report of the ad hoc committee for the re-evaluation of the species definition in bacteriology. Int J Syst Evol Microbiol 52, 1043-1047.
Thompson, J. D., Gibson, T. J., Plewniak, F., Jeanmougin, F. \& Higgins, D. G. (1997). The CLUSTAL $x$ windows interface: flexible strategies for multiple sequence alignment aided by quality analysis tools. Nucleic Acids Res 25, 4876-4882.

Venkateswaran, K., Dohmoto, N. \& Harayama, S. (1998). Cloning and nucleotide sequence of the gyrB gene of Vibrio parahaemolyticus and its application in detection of this pathogen in shrimp. Appl Environ Microbiol 64, 681-687.

Watanabe, K., Nelson, J., Harayama, S. \& Kasai, H. (2001). ICB database: the $g y r B$ database for identification and classification of bacteria. Nucleic Acid Res 29, 344-345.

Yamamoto, S. \& Harayama, S. (1995). PCR amplification and direct sequencing of $\operatorname{gyr} B$ genes with universal primers and their application to the detection and taxonomic analysis of Pseudomonas putida strains. Appl Environ Microbiol 61, 1104-1109.

Yamamoto, S. \& Harayama, S. (1996). Phylogenetic analysis of Acinetobacter strains based on the nucleotide sequences of gyrB genes and on the amino acid sequences of their products. Int $J$ Syst Bacteriol 46, 506-511.

Yamamoto, S. \& Harayama, S. (1998). Phylogenetic relationships of Pseudomonas putida strains deduced from the nucleotide sequences of gyrB, rpoD and 16S rRNA genes. Int J Syst Bacteriol 48, 813-819.

Yamamoto, S., Bouvet, P. J. M. \& Harayama, S. (1999). Phylogenetic structures of the genus Acinetobacter based on gyrB sequences: comparison with the grouping by DNA-DNA hybridization. Int J Syst Bacteriol 49, 87-95.

Yamamoto, S., Kasai, H., Arnold, D. L., Jackson, R. W., Vivian, A. \& Harayama, S. (2000). Phylogeny of the genus Pseudomonas: intrageneric structure reconstructed from the nucleotide sequences of gyrB and rpoD genes. Microbiology 146, 2385-2394. 